IRSTI 29.15.53

\title{
Evaluation of tritium release curve in primary coolant of research reactors
}

\author{
E. Ishitsuka and I. E. Kenzhina* \\ Sector of Nuclear Science Research, Japan Atomic Energy Agency (JAEA), \\ 4002 Narita-cho, Oarai-machi, Higashi Ibaraki-gun, Ibaraki-ken, 311-1393, Japan \\ *e-mail:Inesh.kenzhina@gmail.com
}

\begin{abstract}
Increase of tritium concentration in the primary coolant for the research and testing reactors during reactor operation had been reported. To clarify the tritium sources, a curve of the tritium release rate into the primary coolant for the JMTR and the JRR-3M are evaluated. It is also observed that the amount of released tritium is lower in the case of new beryllium components installation, and increases with the reactor operating cycle. These results show the beryllium components in core strongly affect to the tritium release into the primary coolant. As a result, the tritium release rate is related with produced ${ }^{6} \mathrm{Li}$ by $(\mathrm{n}, \alpha)$ reaction from ${ }^{9} \mathrm{Be}$, and evaluation results of tritium release curve are shown as the dominant source of tritium release into the primary coolant for the JMTR and the JRR-3M are beryllium components. Scattering of the tritium release rate with irradiation time were observed, and this phenomena in the JMTR occurred in earlier time than that of the JRR$3 \mathrm{M}$.
\end{abstract}

Key words: tritium release rate, primary coolant, JMTR, JRR-3M, beryllium components.

PACS number(s): 25.85.Ec, 28.41.Fr

\section{Introduction}

Increase of the tritium concentration in the primary coolant during operation for JMTR (Japan Materials Testing Reactor) and the JRR-3M (Japan Research Reactor-3M) had been reported [1-3] as shown in Figure 1.

To study the sources and mechanism of the tritium release into the primary coolant, data of the tritium release into the primary coolant from 1998 to 2011 were collected from the operation data of the JMTR, the JRR-3M and the JRR-4 (Japan Research Reactor-4) [1]. As a result from the data collection, tritium release rate of the JRR-4 without the beryllium core components did not increase during reactor operation. In contrast, the tritium release rate is about $10 \sim 95$ and $60 \sim 140 \mathrm{~Bq} / \mathrm{Wd}$ in the JRR-3M and the JMTR respectively, which cores contain beryllium components, and the tritium content increases while reactor operates. It is also observed that the amount of released tritium is lower in the case of new beryllium components installation, and increases with the reactor operating cycle. These results show the beryllium components in core strongly affect to the tritium release into the primary coolant. As a possibility of the sources of the tritium release into the primary coolant, the beryllium components by the chains reaction (Figure 1) [4], the ternary fission by the ${ }^{235} \mathrm{U}$ impurity or contamination of core components or fuel plate can be considered. As a possibility of mechanism of the tritium release into the primary coolant, the recoil, the diffusion, etc. can be considered [1, 5]. However, above mentioned results show only the phenomena, and it is not a scientific evidences.

Therefore, as a first step of consideration of sources for the tritium release into the primary coolant, evaluation of the tritium release curve is carried out in this paper [6].

\section{Tritium Release into Primary Coolant}

Outline of the JMTR and the JRR-3M summarized in Table 1. The JMTR is the tank type, and the JRR-3M is pool type research reactors. The primary coolants are light water and coolant temperature is lower than $50^{\circ} \mathrm{C}$. Beryllium core components are used in the both reactors as shown in Figure 2 and Figure 3 [1]. 
Table 1 - Outline of JMTR, JRR-3M

\begin{tabular}{ccc}
\hline Items & JMTR & JRR-3M \\
\hline Thermal power $(\mathrm{MW})$ & 50 & 20 \\
Main purposes & Irradiation tests, & Beam experiments, \\
& RI productions, & \\
& Training & $\mathrm{Be}, \mathrm{D} 2 \mathrm{O}$ tank \\
Main core components & $\mathrm{Be}, \mathrm{Al}$ & $25 \mathrm{~d} / \mathrm{cy}, 6 \mathrm{cy} / \mathrm{y}$ \\
Operation & $30 \mathrm{~d} / \mathrm{cy}, 6 \mathrm{cy} / \mathrm{y}$ & \\
\hline
\end{tabular}

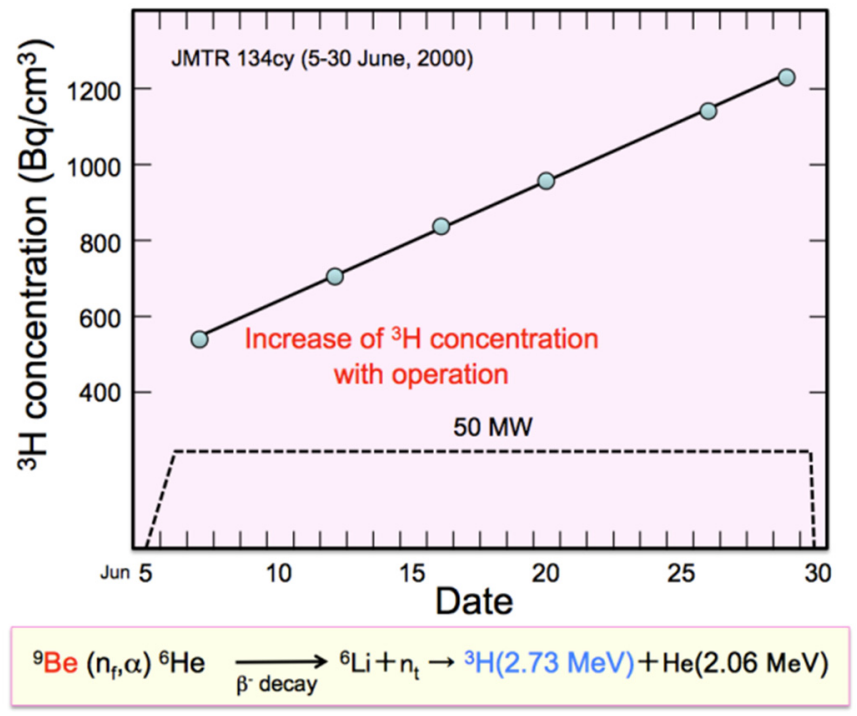

Figure 1 - Tritium concentration of primary coolant in the JMTR

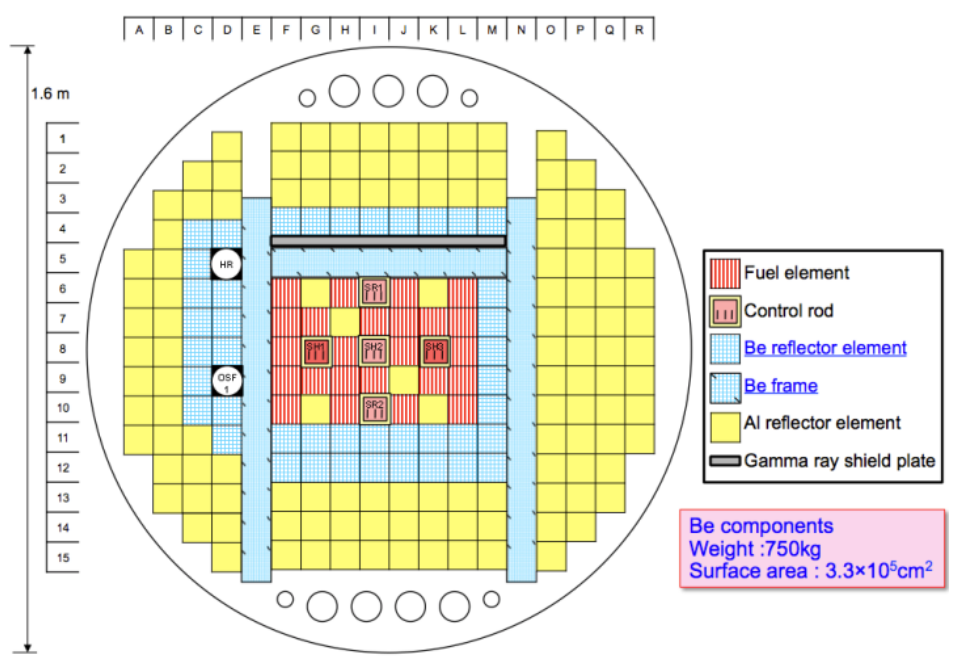

Figure 2 - Core configuration of the JMTR 


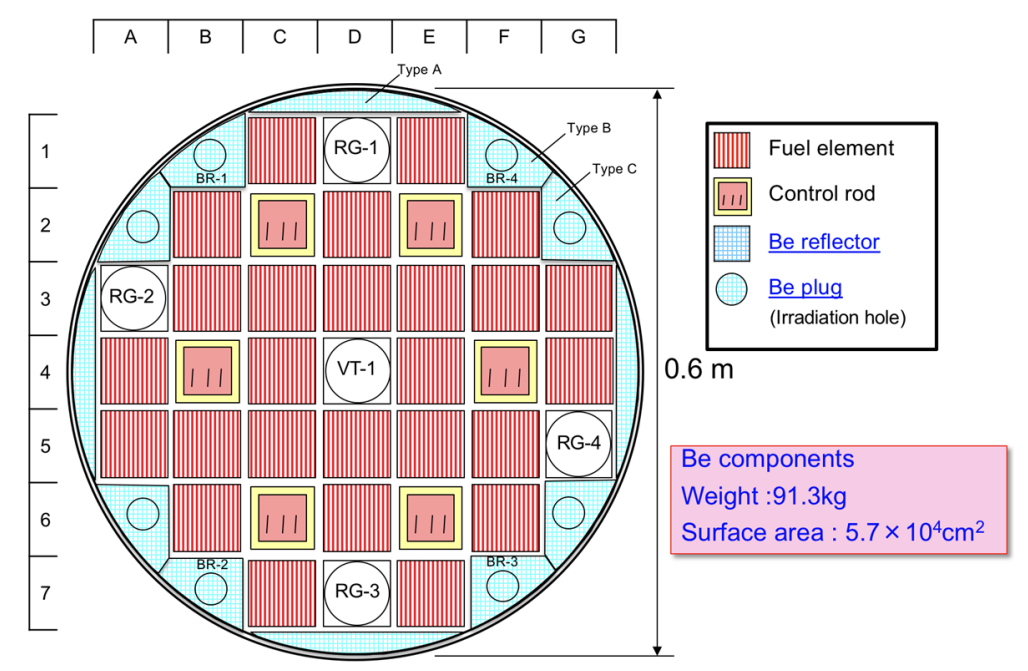

Figure 3 - Core configuration of the JRR-3M

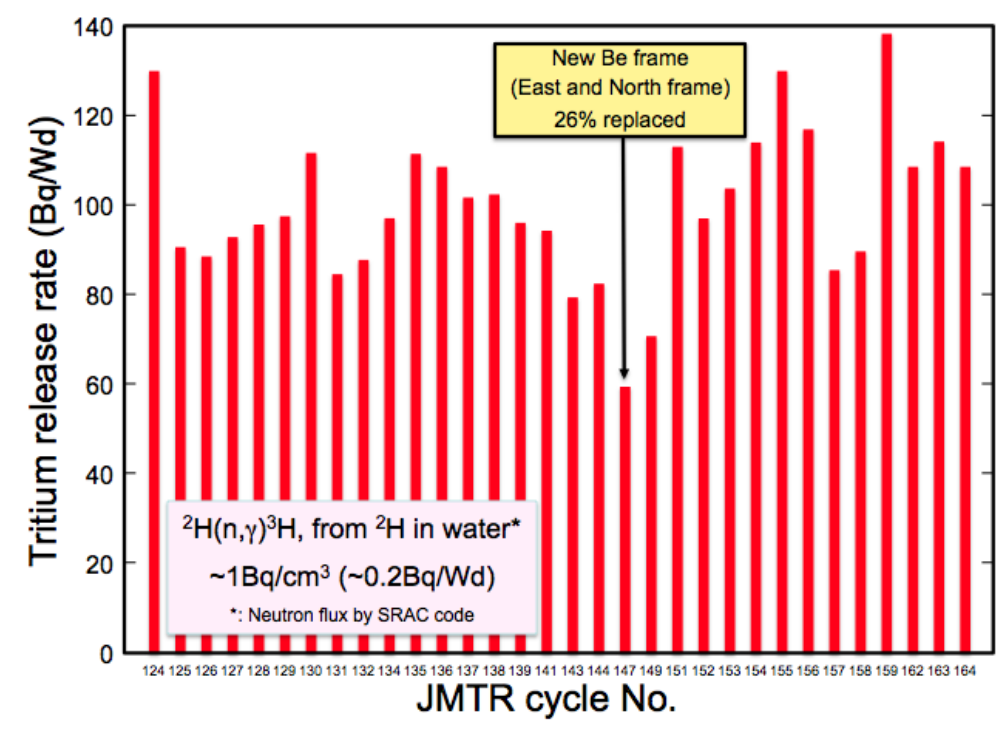

Figure 4 - Tritium release rate of the JMTR

Tritium release rate into the primary coolant for the JMTR operation cycles is shown in Figure 4 [1]. The decrease of tritium release rate is observed in the JMTR $147^{\text {th }}$ cycle corresponded with the replacement of new beryllium frames. This replacement was five times from first criticality, and only an East and North beryllium frames $(198 \mathrm{~kg}$, $26 \%$ of total beryllium components) had replaced in 2002. The tritium production from deuterium from water by $(\mathrm{n}, \square \square)$ reaction was also roughly estimated using the water volume in the core and the neutron flux calculated by SRAC code [1], and it is clear that the tritium production from deuterium from water is less than $0.2 \%$ of the measured tritium concentration, and is negligible [1].

Tritium release rate into the primary coolant for the JRR-3M operation cycle is shown in Figure 5. The decrease of tritium release rate was observed clearly in the JRR-3M R3-15-01 cycle corresponded with the replacement of new beryllium reflectors. In this replacement, all beryllium reflectors $(91.3 \mathrm{~kg})$ had replaced in 2010. 


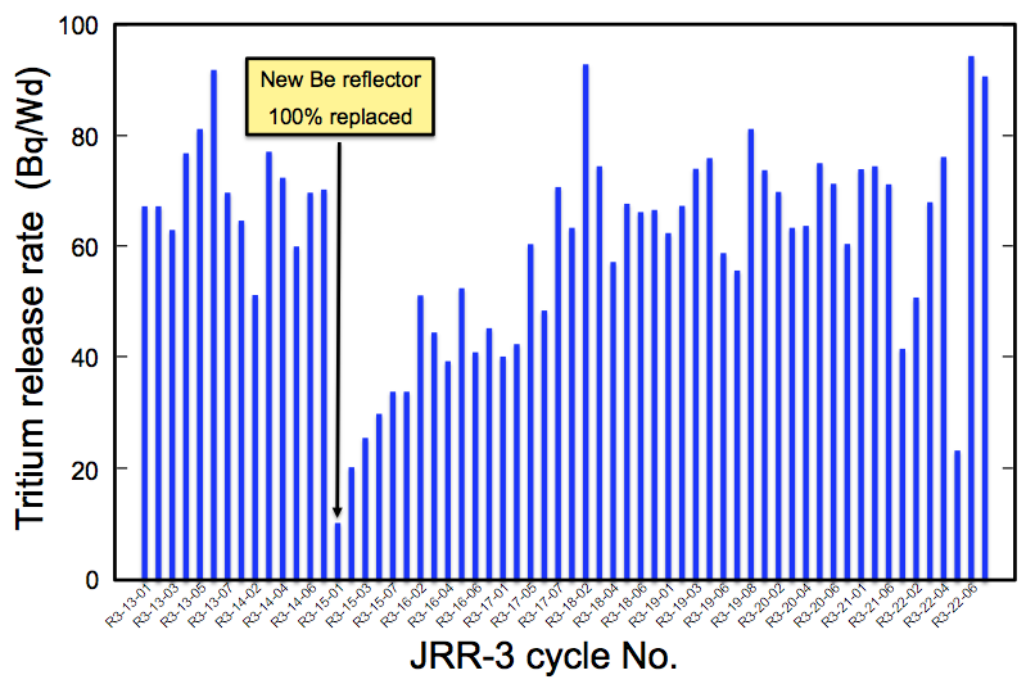

Figure 5 - Tritium release rate of JRR-3M

Table 2 - One group cross sections

\begin{tabular}{ccccc}
\hline Nuclide & Nuclear reaction & Production & $\begin{array}{c}\text { Cross section (barn) } \\
\text { at Be in JMTR }\end{array}$ & $\begin{array}{c}\text { Cross section (barn) } \\
\text { at Be in JRR-3M }\end{array}$ \\
\hline${ }^{6} \mathrm{Li}$ & $\left(\mathrm{n}_{\mathrm{t},}, \alpha\right)$ & ${ }^{3} \mathrm{H}$ & $4.53 \times 10^{2}$ & $2.86 \times 10^{2}$ \\
${ }^{9} \mathrm{Be}$ & $\left(\mathrm{n}_{\mathrm{f}, \alpha)}\right.$ & ${ }^{6} \mathrm{He}\left({ }^{6} \mathrm{Li}\right)$ & $2.29 \times 10^{-3}$ & $6.11 \times 10^{-3}$ \\
${ }^{235} \mathrm{U}$ & Thermal-fission & $\mathrm{FP}$, & $2.73 \times 10^{2}$ & $1.73 \times 10^{2}$ \\
${ }^{238} \mathrm{U}$ & Fast-fission & $\left(1.19 \times 10^{-4 *}\right)$ & $\mathrm{FP}$, \\
\hline
\end{tabular}

*: Cumulative yield of ${ }^{3} \mathrm{H}$

\section{Tritium Release into Primary Coolant}

Tritium generation from ${ }^{9} \mathrm{Be}$ was considered by the following chain reactions [4].

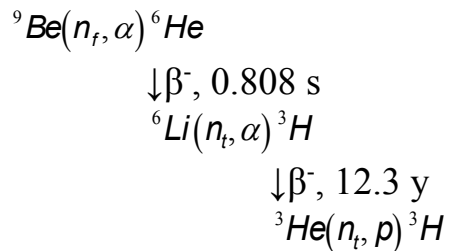

$$
\begin{gathered}
\frac{d N_{B e}}{d t}=-\sigma_{B e} \phi_{f} N_{B e} \\
\frac{d N_{L i}}{d t}=\sigma_{B e} \phi_{f} N_{B e}-\sigma_{L i} \phi_{t} N_{L i}
\end{gathered}
$$

where, the meanings of the symbols are as follows;
$N_{B e}:{ }^{9} \mathrm{Be}$ atoms density
$N_{L i}:{ }^{6} \mathrm{Li}$ atoms density
$\left(1 / \mathrm{cm}^{3}\right)$
$\left(1 / \mathrm{cm}^{3}\right)$
$\sigma_{B e}$ : Cross section of ${ }^{9} \mathrm{Be}\left(\mathrm{n}_{\mathrm{f}}, \alpha\right)^{6} \mathrm{He}$ (barn)
$\sigma_{L i}$ : Cross section of ${ }^{6} \mathrm{Li}\left(\mathrm{n}_{\mathrm{t}}, \alpha\right)^{3} \mathrm{H} \quad$ (barn)
$\varphi_{f}:$ Fast neutron flux $\quad\left(\mathrm{n} / \mathrm{cm}^{2} / \mathrm{s}\right)$
$\varphi_{t}:$ Thermal neutron flux $\quad\left(\mathrm{n} / \mathrm{cm}^{2} / \mathrm{s}\right)$ 
Hereafter, $\varphi f=\varphi t=\varphi$, because neutron spectrum is one energy group. One group cross sections obtained from the evaluated nuclear data library JENDL-4.0[7] by averaging with the neutron spectra calculated for the beryllium core components of the JMTR and the JRR-3M are summarized in Table 2. By solving the equation (1) and (2) using the initial conditions $N L i(t)=0$ at $t=$ 0 , the following equations are obtained.

$$
\begin{gathered}
N_{B e}(t)=N_{B e}(0) e^{-\sigma_{B e} \rho t} \\
N_{L i}(t)=\frac{N_{B e}(0) \sigma_{B e}}{\left(\sigma_{L i}-\sigma_{B e}\right)}\left(e^{-\sigma_{B e} \rho t}-e^{-\sigma_{L} \phi t}\right)
\end{gathered}
$$

in this case $(\sigma \mathrm{Li} \gg>\sigma \mathrm{Be})$, the generated ${ }^{6} \mathrm{Li}$ atoms by neutron irradiation are shown as next equation [8].

$$
N_{L i}(t)=\frac{\sigma_{B e}}{\sigma_{L i}} N_{B e}(0)\left(1-e^{-\sigma_{L i} \phi t}\right)
$$

Neutron flux of $\varphi=2.68 \times 10^{14}\left(\mathrm{n} / \mathrm{cm}^{2} / \mathrm{s}\right)$ for the JMTR and $\varphi=1.42 \times 10^{14}\left(\mathrm{n} / \mathrm{cm}^{2} / \mathrm{s}\right)$ for the JRR-3M [1], and one group cross sections from Table 2, the time dependent terms of ${ }^{6} \mathrm{Li}$ atoms number were calculated as; $[1-\exp (-1.21 \times 10-7 t)]$ for the JMTR and $[1-\exp (-4.07 \times 10-8 t)]$ for the JRR-3M, respectively.

Curve fittings using released tritium data for new beryllium compornents installation were carried out. When magnitude selects as 120 for the JMTR and 75 for the JRR-3M, the calculated curves are closest to the experimental data, and are shown in Figure 6 and 7. Equation (5) for the JMTR and the JRR-3M are described as following equations.

\section{JMTR;}

$$
N_{L i}(t) \propto 120 \times\left[1-\exp \left(-1.21 \times 10^{-7} t\right)\right]
$$

JRR-3M;

$$
N_{L i}(t) \propto 75 \times\left[1-\exp \left(-4.07 \times 10^{-8} t\right)\right]
$$

Especially, in the early periods of the JRR-3M, the released tritium shows the good agreement with calculated curve by the equation (7). This reason is considerd that effects of the replacement of beryllium reflectors for the JRR-3M is more clealy than that of the JMTR because the replacement rate of beryllium components are larger than that of the JMTR.

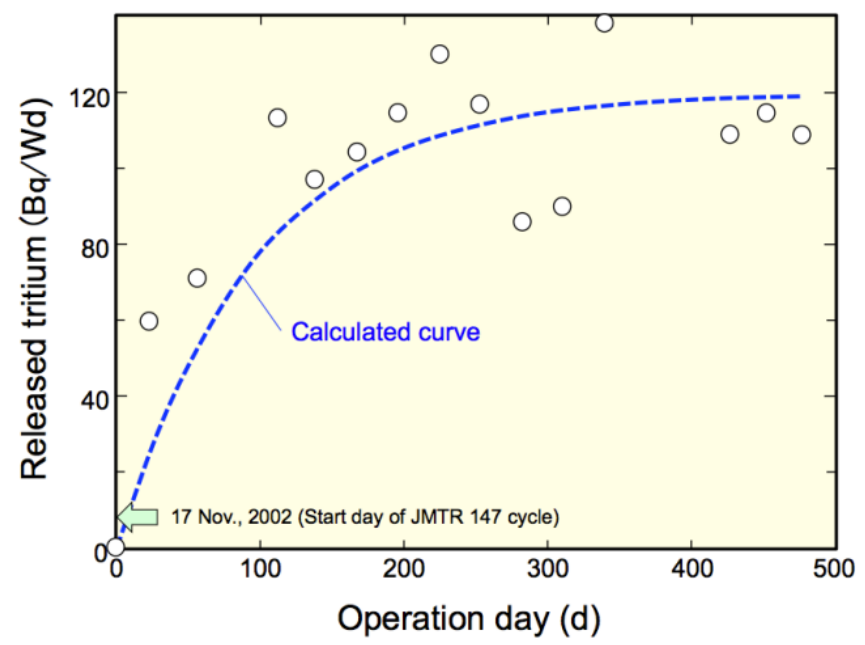

Figure 6 - Curve fitting of released tritium and ${ }^{6} \mathrm{Li}$ atoms number in beryllium components for JMTR 


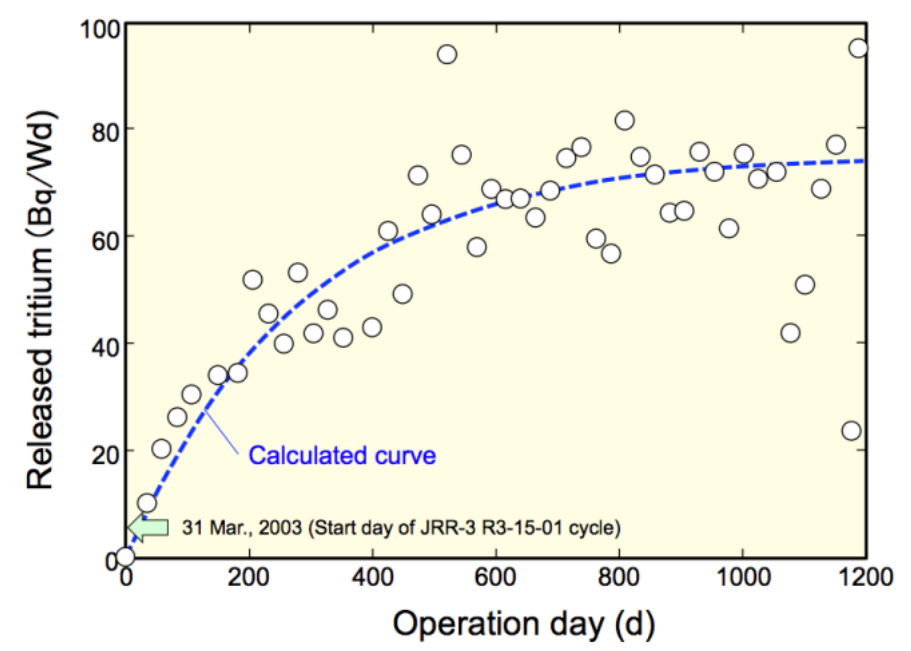

Figure 7 - Curve fitting of released tritium and ${ }^{6} \mathrm{Li}$ atoms number in beryllium components for JRR-3M

\section{Discussion}

Results of the curve fittings suggeste the tritium release rate into the primary coolant is related with the number of produced ${ }^{6} \mathrm{Li}$ by $(\mathrm{n}, \alpha)$ reaction from ${ }^{9} \mathrm{Be}$, and this reaction recognized as a dominant for the tritium release into the primary coolant.

In the early periods of the JRR-3M, the released tritium show the good agreement with calculated curve by the equation (7). However, the data are scattered with irradiation time. This reason is presumably caused by the measurement error and effects of $\mathrm{He}$ bubbles produced by the neutron irradiation $[9,10]$. This tendency is also observed in the JMTR such as Figure 4 and Figure 6 show. Additionally, this phenomena in the JMTR is observed in earlier than that of the JRR-3M because of higher neutron fluence.

Summary of the candidates of tritium source is shown in Table 3. Tritium release by the ternary fission from ${ }^{235} \mathrm{U}$ as the impurity in core components can estimate smaller than beryllium, however, more detail calculations will be nessary to prove it. As a release mechnism, the consideration of the diffusion, the recoil and effects by the He production are nessesary. To study in details, the calculation methods of the recoil which include the impurities like as $\mathrm{Li}$ and $\mathrm{U}$ are studying by PHITS code $[11,12]$.

Table 3 - Candidates of tritium source

\begin{tabular}{cccc}
\hline Element & Reactions & Core components, etc. & Role as tritium source \\
\hline${ }^{2} \mathrm{H}$ & $(\mathrm{n}, \gamma)$ & Coolant & $<0.2 \mathrm{~Bq} / \mathrm{Wd}$ in JMTR, Negligible $[1]$ \\
${ }^{9} \mathrm{Be}$ & $\left(\mathrm{n}_{\mathrm{f}}, \alpha\right){ }^{6} \mathrm{He} \&{ }^{6} \mathrm{Li}\left(\mathrm{n}_{\mathrm{t}}, \alpha\right)$ & $\begin{array}{c}\text { Beryllium components } \\
\text { (reflectors, frame) } \\
\text { Contamination of fuel plate }\end{array}$ & Dominant (in this paper) \\
${ }^{235} \mathrm{U}$ & Ternary fission & $\begin{array}{c}\text { Impurity of beryllium components } \\
\text { Impurity of other components }\end{array}$ & Future study \\
\hline
\end{tabular}

\section{Conclusions}

Therefore, curves of the tritium release rate into the primary coolant in the JMTR and the JRR-3M were evaluated. Curves of the tritium release rate into the primary coolant is related with number of produced ${ }^{6} \mathrm{Li}$ by $(\mathrm{n}, \alpha)$ reaction from ${ }^{9} \mathrm{Be}$. Also, the tritium release rate in early periods of the JRR-3M shows the good agreement with calculated curve. Evaluation results of tritium release curve are shown as the dominant source of tritium release into the primary coolant for the JMTR and the JRR-3M are 
beryllium components. Moreover, it has been noticed that scattering of the tritium release rate with irradiation time was observed, and that phenomena in the JMTR occurred in earlier time than that of the JRR-3M.

\section{Acknowledgments}

The authors greatly appreciate the helpful comments on this paper by Mr. Byung Jin Jun (2009-2010 JAEA Research Fellow).

\section{References}

1. E. Ishitsuka, J. Motohashi, Y. Hanawa, M. Komeda, S. Watahiki, A. Mukanova, I. Kenzhina, Y. Chikhray. Study of origin on tritium release into primary coolant for research and testing reactors. Tritium release rate evaluated from JMTR, JRR-3M and JRR-4 Operation Data // JAEA-Technology. - 2014. - Vol. 025.

2. N. Terunuma, Y. Nagao, I. Yokouchi, M. Sato. Concentration of Radio Active Elements in Primary Cooling Water at Reactor Operation of JMTR // JAEA-Review. - 2007. - Vol. 034.

3. Department of research reactor. Annual report of department of research reactor, 1991 (April 1, 1991 March 31, 1992) // JAERI-M 92. 1992. - Vol. 154.

4. S. Shimakawa, E. Ishitsuka, M. Saito. HEINBE, the calculation program for helium production in beryllium under neutron irradiation // JAERI-M 92. 1992. - Vol. 174

5. E. Ishitsuka, H. Kawamura, H. Sugai, M. Tanase, H. Nakata. Experiments on tritium behavior in beryllium (2), Tritium Released by Recoil and Diffusion // JAERI-M 90. 1990. - Vol. 013.

6. I. Kenzhina et al. Evaluation of curve for tritium release rate into primary coolant of research and testing reactors // 4th Asian Symposium on Material Testing Reactors, Hanoi, Vietnam, 3-4 March 2016. - P. 45.

7. K. Shibata, O. Iwamoto, T. Nakagawa, N. Iwamoto, A. Ichihara, S. Kunieda, S. Chiba, K. Furutaka, N. Otuka, T. Ohsawa, T. Murata, H. Matsunobu, A. Zukeran, S. Kamada, and J. Katakura. JENDL-4.0: A new library for nuclear science and engineering // J. Nucl. Sci. Technol. - 2011. - Vol. 48(1). - P. 1-30.

8. K. Sezaki, K. Takeda, F. Sakurai, B. Komukai, I. Kondo. Correspondence between JMTR and JMTRC (No. 34 operation cycle) // JAERI-M-6686.- 1976.

9. M. Dalle Donne, D.L. Baldwin, D.S. Gelles, L.R. Green-wood, H. Kawamura, B.M. Oliver, F. Scadi-Argentina. Behavior of beryllium pebble under irradiation // JAERI- Conf 98-001. - 1998. - P. 296.

10. E. Ishitsuka, H. Kawamura, T. Terai, S. Tanaka. Effects of helium production and radiation damage on tritium release behavior of neutron-irradiated beryllium pebbles // J. Nucl. Mater. - Vol. 283-287. - P. 1401-1404.

11. T. Sato, K. Niita, N. Matsuda, S. Hashimoto, Y. Iwamoto, S. Noda, T. Ogawa, H. Iwase, H. Nakashima, T. Fukahori, K. Okumura, T. Kai, S. Chiba, T. Furuta and L. Sihver. Particle and Heavy Ion Transport Code System PHITS, Version 2.52 // J. Nucl. Sci. Technol. - 2013. - Vol. 50:9. - P. 913-923.

12. E. Ishitsuka, I. Kenzhina, K. Okumura, N. Takemoto and Y. Chikhray. Calculation by PHITS Code for Recoil Tritium Release Ratefrom Beryllium under Neutron Irradiation // JAEA-Technology 2016-022. - 2016. 